\title{
Preface for the article collection "High- Pressure Earth and Planetary Science in the last and next decade"
}

\author{
Tatsuya Sakamaki ${ }^{*}$, Akio Suzuki $^{1}$ and Bjorn Mysen ${ }^{2}$
}

Keywords: High pressure, Early earth, Magma, Fluid, Mantle, Core, Synchrotron X-ray

\section{Preface}

A special session entitled "Early Earth - from accumulation to formation-" was held on May 24, 2015 during the Japan Geoscience Union (JpGU) annual meeting. This session aimed to bring together high-pressure/hightemperature experiment on physics and chemistry of deep Earth materials, natural observation, and theoretical modeling within the principal subject areas of "Early Earth" research. Twenty-six oral and seven poster presentations were given at this session (Fig. 1). Two review and seven research articles from that session are included in this SPEPS. These articles cover Earth's formation/evolution (de Vries et al. 2016; Kondo et al. 2016), magma and fluid in the interior of the Earth (Mysen 2015; Ohira et al. 2016; Poli 2016; Reynard 2016), Earth's deep mantle (McCammon et al. 2016; Zhang et al. 2016), and methods using synchrotron radiation (Yu et al. 2016).

Giant impact events during planetary accretion caused large degrees of melting of the early Earth. De Vries et al. (2016) simulated the volumes of melt, pressure, and temperature conditions of metal-silicate equilibration after each impact, and demonstrated that the pressure evolution during metal-silicate equilibration during accretion depends strongly on the lifetime of impactgenerated magma oceans compared to the time interval between large impacts. Kondo et al. (2016) estimated major element composition of an early Earth reservoir (EER) with the aid of ${ }^{142} \mathrm{Nd} /{ }^{144} \mathrm{Nd}$ isotope systematics to determine the age and pressure-temperature conditions to form the EER. They concluded that the EER formed within 33.5 Myr of Solar System formation and at

\footnotetext{
*Correspondence: sakamaki@m.tohoku.ac.jp

${ }^{1}$ Department of Earth Science, Tohoku University, 6-3, Aramaki Aza-Aoba,

Aoba-ku, Sendai 980-8578, Japan

Full list of author information is available at the end of the article
}

near-solidus temperatures and pressures of shallow upper mantle conditions. The picritic to komatiitic crust (EER) most likely would have been ejected from the Earth by the last giant impact or preceding impacts. They concluded, therefore, the EER was lost, leaving the Earth more depleted than its original composition.

The existence of magma and fluid is one of the most unique features of the Earth. These materials are principal agents of mass and energy transfer in and on the Earth and are, therefore, responsible for the many unique features of formation, evolution, and present day processes of the Earth. In subduction zone environments, fluids are particularly important. With this consideration in mind, Poli (2016) studied the melting carbonated epidote eclogites. The subsolidus breakdown of epidote in the presence of carbonates at depths exceeding $120 \mathrm{~km}$ provides a major source of $\mathrm{C}-\mathrm{O}-\mathrm{H}$ volatiles at sub-arc depth. In warm subduction zones, the possibility of extracting carbonatitic liquids from a variety of gabbroic rocks and epidosites offers new scenarios on the metasomatic processes in the lithospheric wedge of subduction zones and a new mechanism for recycling carbon. Reynard (2016) reviewed the mantle hydration and $\mathrm{Cl}$-rich fluids in the subduction forearc. Mysen (2015) reported the $\mathrm{Zr}^{4+}$ transport capacity of water-rich fluids. His results imply that fluid released during high-temperature/high-pressure dehydration of hydrous mineral assemblages in the Earth's interior under some circumstances may carry significant concentrations of $\mathrm{Zr}$.

In order to further our understanding of the nature of dense silicate melts that may be present at the base of the mantle, Ohira et al. (2016) used Brillouin scattering spectroscopic methods to pressures of $196.9 \mathrm{GPa}$ to conduct in situ high-pressure acoustic wave velocity 


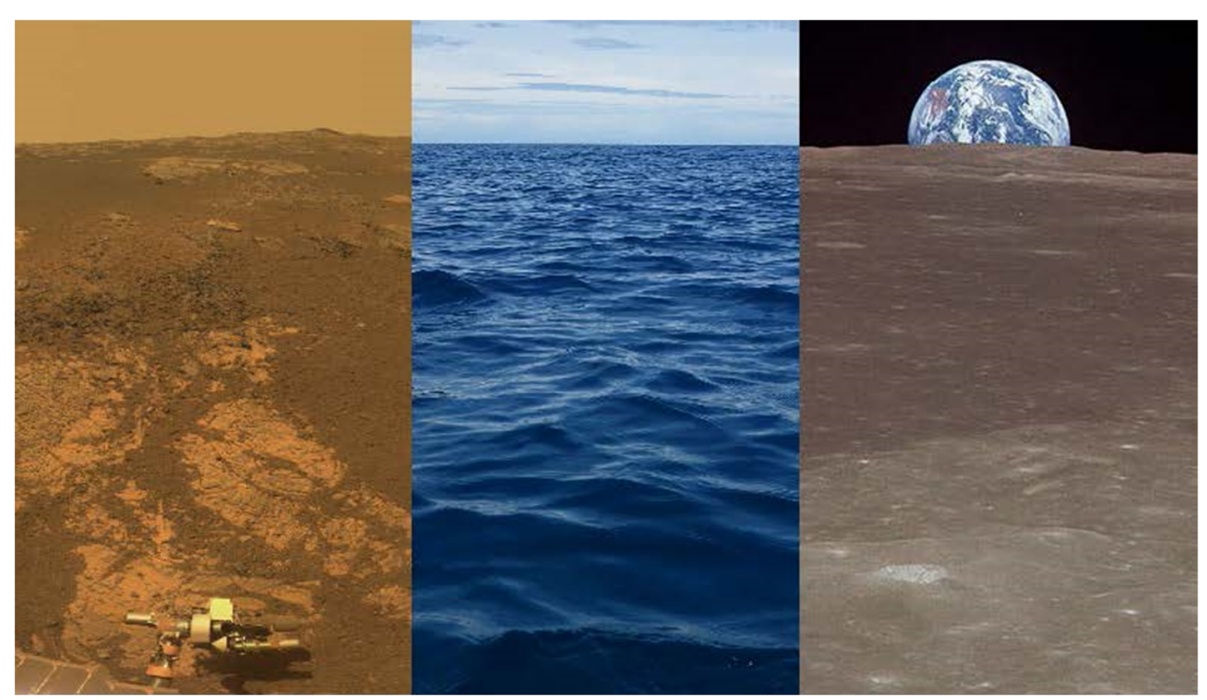

Fig. 1 Poster used for the special call for excellent papers on hot topics: "High-Pressure Earth and Planetary Science in the last and next decade". From left to right: the surface of Mars, Earth, and Moon

measurements of $\mathrm{SiO}_{2}-\mathrm{Al}_{2} \mathrm{O}_{3}$ glasses. Compared to previous acoustic wave velocity data on $\mathrm{SiO}_{2}$ and $\mathrm{MgSiO}_{3}$ glasses, $\mathrm{Al}_{2} \mathrm{O}_{3}$ appears to promote a lowering of the pressure at which the abrupt increase of $d V{ }_{S} / d P$ is observed. This suggests that the $\mathrm{Al}_{2} \mathrm{O}_{3}$ in silicate melts may help to stabilize gravitationally those melts in the lower mantle.

The properties of mantle minerals in the deep Earth are important research target. McCammon et al. (2016) reported Debye sound velocities by using nuclear inelastic scattering for one majorite composition and five bridgmanite compositions measured in a diamond anvil cell at pressures up to $89 \mathrm{GPa}$ at room temperature. They calculated partial and total density of states (DOS) for $\mathrm{MgSiO}_{3}$ and $\mathrm{FeSiO}_{3}$ bridgmanite by using density functional theory. It was demonstrated that Debye sound velocities calculated from the reduced DOS with the same approach as for the experimental data give the same sound velocities for each phase irrespective of which partial DOS is used. Zhang et al. (2016) reported accurate unit cell parameters of individual mineral phases in a mineral assemblage contained in a diamond anvil cell (DAC) with the aid of multigrain X-ray diffraction (XRD) technique. Coexisting post-perovskite (ppv) and $\mathrm{H}$-phase were synthesized at $119 \mathrm{GPa}$ and $2500 \mathrm{~K}$ from $\left(\mathrm{Mg}_{0.85} \mathrm{Fe}_{0.15}\right) \mathrm{SiO}_{3}$ in a laser-heated DAC. Their unit cell parameters were determined using multigrain XRD with $5 \mu \mathrm{m}$ spatial resolution, to advance our understanding of compositional variations across the center area in a laser-heated sample.

Synchrotron X-ray is an important tool in highpressure Earth science. Yu et al. (2016) reviewed the high-pressure X-ray microtomography (HPXMT), which can provide the high-pressure community with a unique opportunity to image the three-dimensional volume, texture, and microstructure of materials under high pressure and temperature by combining the strong synchrotron X-ray source and fast switching between white (for X-ray diffraction) and monochromatic (for absorption imaging) modes.

Finally, we dedicate this SPEPS to Dr. E. Ohtani (professor emeritus at Tohoku University), who made meaningful contributions to vast research areas from partial melting of deep silicate Earth, element partitioning, and role of hydrous circulation of water and hydrogen in the early deep Earth to core/mantle equilibria together with equation-of-state of silicate mantle and metal core materials. It is striking how many current research directions were initiated by Professor Ohtani decades ago and how involved he remains even today. There is hardly any subject where he and his collaborators contributed often the original and often the most important experimental data and demonstrated how these can be used to model the physics and chemistry of the materials and processes in the interior of the Earth and terrestrial planets. We hope that this SPEPS will also convey this message.

\section{Acknowledgements}

This special issue is based on a special session entitled "Early Earth - from accumulation to formation-" held on May 24, 2015 at the Japan Geoscience Union (JpGU) annual meeting in Makuhari. The session consisted of 26 oral and seven poster presentations, and included 11 presentations from outside Japan. The session was highly successful, with energetic discussions, and resulted in nine articles being submitted to this special issue. Travel expenses of invited speakers from outside Japan were supported by JpGU, and we thank PEPS staff for logistical help provided to foreign participants. We would like to acknowledge the authors and reviewers for their valuable contributions. We thank Prof. Yasufumi Iryu for serving as a General Chief 
Editor. We also thank Ms. Tomoyo Asada and other PEPS staff for their support during the submission and revision of manuscripts, and the PEPS editorial board for helpful and swift editorial handling of manuscripts.

\section{Funding}

Not applicable.

\section{Authors' contributions}

All authors wrote this manuscript and approved the final manuscript.

\section{Competing interests}

The authors declare that they have no competing interests.

\section{Author details}

'Department of Earth Science, Tohoku University, 6-3, Aramaki Aza-Aoba, Aoba-ku, Sendai 980-8578, Japan. ${ }^{2}$ Geophysical Laboratory, Carnegie Institution of Washington, 5251 Broad Branch Rd., NW, Washington, DC 20015, USA.

Received: 29 November 2016 Accepted: 29 November 2016

Published online: 15 December 2016

\section{References}

de Vries J, Francis N, Jay Melosh H, Jacobson SA, Morbidelli A, Rubie DC (2016) Impact-induced melting during accretion of the Earth. Prog Earth Planet Sci 3:7. doi:10.1186/s40645-016-0083-8

Kondo N, Yoshino T, Matsukage KN, Kogiso T (2016) Major element composition of an early enriched reservoir: constraints from ${ }^{142} \mathrm{Nd} /{ }^{144} \mathrm{Nd}$ isotope systematics in the early Earth and high-pressure melting experiments of a primitive peridotite. Prog Earth Planet Sci 3:25. doi:10.1186/s40645-016-0099-0

McCammon C, Caracas R, Glazyrin K, Potapkin V, Kantor A, Sinmyo R, Prescher C, Kupenko I, Chumakov A, Dubrovinsky L (2016) Sound velocities of bridgmanite from density of states determined by nuclear inelastic scattering and first principles calculations. Prog Earth Planet Sci 3:10. doi:10.1186/ s40645-016-0089-2

Mysen B (2015) An in-situ experimental study of $Z r^{4+}$ transport capacity of water-rich fluids in the temperature and pressure range of the deep crust and upper mantle. Prog Earth Planet Sci 2:38. doi:10.1186/s40645-015-0070-5

Ohira I, Murakami M, Kohara S, Ohara K, Ohtani E (2016) Ultrahigh-pressure acoustic wave velocities of $\mathrm{SiO}_{2}-\mathrm{Al}_{2} \mathrm{O}_{3}$ glasses up to $200 \mathrm{GPa}$. Prog Earth Planet Sci 3:18. doi: 10.1186/s40645-016-0097-2

Poli S (2016) Melting carbonated epidote eclogites: carbonatites from subducting slabs. Prog Earth Planet Sci 3:27. doi:10.1186/s40645-016-0105-6

Reynard B (2016) Mantle hydration and Cl-rich fluids in the subduction forearc. Prog Earth Planet Sci 3:9. doi: 10.1186/s40645-016-0090-9

Yu T, Wang Y, Rivers ML (2016) Imaging in 3D under pressure: a decade of high-pressure X-ray microtomography development at GSECARS. Prog Earth Planet Sci 3:17. doi:10.1186/s40645-016-0093-6

Zhang L, Meng Y, Mao H-K (2016) Unit cell determination of coexisting postperovskite and $\mathrm{H}$-phase in (Mg, $\mathrm{Fe}) \mathrm{SiO}_{3}$ using multigrain XRD: compositional variation across a laser heating spot at $119 \mathrm{GPa}$. Prog Earth Planet Sci 3:13. doi: 10.1186/s40645-016-0091-8

\section{Submit your manuscript to a SpringerOpen ${ }^{\mathcal{O}}$ journal and benefit from:}

- Convenient online submission

$\checkmark$ Rigorous peer review

- Immediate publication on acceptance

- Open access: articles freely available online

- High visibility within the field

- Retaining the copyright to your article 